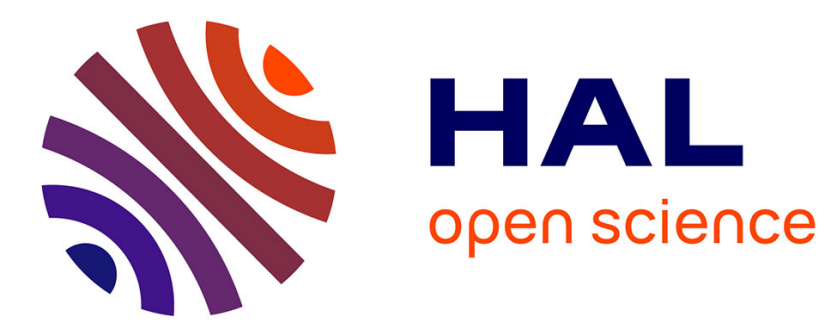

\title{
Periodic DFT Study of Rutile IrO2 : Surface Reactivity and Catechol Adsorption
}

\author{
Olivier Matz, Monica Calatayud
}

\section{To cite this version:}

Olivier Matz, Monica Calatayud. Periodic DFT Study of Rutile IrO2 : Surface Reactivity and Catechol Adsorption. Journal of Physical Chemistry C, 2017, 10.1021/acs.jpcc.7b01990 . hal-01537843

\section{HAL Id: hal-01537843 https://hal.sorbonne-universite.fr/hal-01537843}

Submitted on 13 Jun 2017

HAL is a multi-disciplinary open access archive for the deposit and dissemination of scientific research documents, whether they are published or not. The documents may come from teaching and research institutions in France or abroad, or from public or private research centers.
L'archive ouverte pluridisciplinaire HAL, est destinée au dépôt et à la diffusion de documents scientifiques de niveau recherche, publiés ou non, émanant des établissements d'enseignement et de recherche français ou étrangers, des laboratoires publics ou privés. 
A Periodic DFT Study of Rutile $\mathrm{IrO}_{2}$ : Surface Reactivity and

\title{
Catechol Adsorption
}

\author{
Olivier Matz ${ }^{1}$, Monica Calatayud ${ }^{1,2, *}$ \\ ${ }^{1}$ Sorbonne Universités, UPMC Univ Paris 06, CNRS, Laboratoire de Chimie Théorique \\ CC 137 - 4, place Jussieu, F. 75252 PARIS CEDEX 05 - France \\ ${ }^{2}$ Institut Universitaire de France, F-75005, Paris, France
}

\begin{abstract}
${ }^{*}$ Corresponding author: Dr. Hab. Monica Calatayud
Sorbonne Universités, UPMC Univ Paris 06, CNRS, Laboratoire de Chimie Théorique

CC 137 - 4, place Jussieu, F. 75252 PARIS CEDEX 05 - France

e-mail : calatayu@1ct.jussieu.fr

phone : +33144272505 fax: +33144274117
\end{abstract}




\begin{abstract}
$\mathrm{IrO}_{2}$ is a key material for photocatalytic applications as water oxidation catalyst. Despite its increasing interest, little is known about its molecular structure and reactivity. In this study, the surface properties of stoichiometric rutile $\mathrm{IrO}_{2}$ are investigated by means of periodic density functional theory (DFT), including the structural, energetic, electronic properties and chemical reactivity towards catechol, a probe molecule mimicking photocatalytic linkers. Our results show that the (110)- $\mathrm{IrO}_{2}$ rutile termination is the most stable, and we discuss the role of the number and type of surface sites in the relative stability compared with (100), (001) and (101) terminations. Regarding the reactivity of the surfaces with catechol, our results show that the molecule dissociates and binds in bidentate, chelate and monodentate modes. Interestingly, we find the chelated mode selectively favored over the (001) termination with the highest adsorption energy $-3.93 \mathrm{eV}$, being unstable on other terminations. The bidentate mode is preferred on (110) $-3.83 \mathrm{eV},(100)-3.24 \mathrm{eV},(101)-2.23 \mathrm{eV}$. The selective stabilization of the chelated mode, suggested in the literature to be responsible for the optical absorption in $\mathrm{TiO}_{2}$ nanoparticles, could guide in the search of tailored iridia-based interfaces for photocatalytic applications.
\end{abstract}




\section{Introduction}

In a photo-electrochemical cell (PEC), the solar energy is used for splitting the water into hydrogen and oxygen molecules ${ }^{1}$. In a time deeply hit by ecological crisis and global warming, the solar hydrogen production seems to be the ideal solution due to the inexhaustible resource of water and the non-emission of pollutant and greenhouse gases ${ }^{2-4}$. In this context, iridium oxide is receiving nowadays increasing interest because of its high efficiency in photocatalytic devices, playing a key role as water oxidation catalyst ${ }^{5-7}$ in the water splitting reaction, in particular for the oxygen evolution reaction (OER):

$$
2 \mathrm{H}_{2} \mathrm{O}=\mathrm{O}_{2}+4 \mathrm{H}^{+}+4 e^{-}
$$

In PEC, the dyes are used to bridge the different materials and so they must bind strongly to the surface of these materials. In addition, the anchoring groups must ensure an appropriate electron transfer between the different parts. Moreover, dyes must be easily photoexcitable in order to show a wide absorption in the visible spectra.

Despite the promising properties of iridium oxide for PECs, the detailed knowledge of the structure and reactivity of $\mathrm{IrO}_{2}$ is still very poor. Indeed, although the structural ${ }^{8-10}$, electronic $^{7,11-14}$, conductivity ${ }^{15,16}$ and optic ${ }^{16-19}$ properties are well known for the bulk of iridium oxide, there is an evident lack of knowledge regarding the surface properties and the surface reactivity of this material. In particular, an atomic description of the surfaces is missing, limiting the knowledge and the interpretation of the physico-chemical phenomena taking place. In the present study, we characterize the structural and electronic properties of stoichiometric low index surfaces and investigate their reactivity towards catechol, a test molecule mimicking common linkers used in photocatalytic devices. The aim is to provide fundamental understanding of the interfaces on the molecular level, that can guide in the search of novel systems with tailored properties. 
Experimental studies mainly focus on photocatalytic applications, and surface science reports are scarce compared to the abundant literature on isostructural rutile $\mathrm{TiO}_{2}$. The most stable termination is the (110). This surface was characterized both experimentally ${ }^{20,21}$ and by means of $\mathrm{DFT}^{22}$, and almost all theoretical studies are focused on it. A combination of surface science and Density Functional Theory (DFT) has been used to support the stability of the oxygen rich (100) iridia termination ${ }^{23}$. Sen et al. ${ }^{24}$ have used DFT to parametrize a force field for $\mathrm{IrO}_{2}$ nanoparticles. Novell-Leruth et al. ${ }^{22}$ have studied the mixture of different rutile oxides and give a brief description of the structural and energetic properties for $\mathrm{IrO}_{2}$ surfaces. More recently, the role of hydration and $\mathrm{Ir}^{4+} / \mathrm{Ir}^{3+}$ interplay has been suggested as being responsible for the observed optical response of $\mathrm{IrO}_{2}$ with a combined Raman-DFT approach $^{25}$. As regards surface reactivity, the oxidation of ammonia ${ }^{26}$, the dissociation of methane ${ }^{27}$ and the role of peroxo intermediates in the oxygen evolution reaction mechanism ${ }^{28}$ has been investigated theoretically. Also, the plausibility of hybrid molecular-surface iridiumbased materials has been supported by theoretical calculations ${ }^{29}$ for the same reaction. Finally, the optical spectroscopic response of a dye adsorption system containing $\mathrm{TiO}_{2}-\mathrm{IrO}_{2}$ has been described ab initio with a realistic model confirming the importance of the surface-molecule interaction in the properties of photo-electrochemical devices ${ }^{30}$. It appears that to the best to our knowledge, there are no works providing a general picture of the structural, energetic, electronic properties of $\mathrm{IrO}_{2}$ surfaces, in particular addressing their interaction with dyes from a molecular point of view. The aim of the present paper is to provide valuable information about the structure and reactivity of iridium dioxide surfaces. Special attention will be paid to the interface between the surfaces and the catechol molecule, used as a model for dye adsorption systems. Geometric parameters, energetics and electronic structure will be used in the analysis and characterization of such model adsorption systems. 


\section{Methods}

\section{A. Computational details}

The properties and reactivity of rutile $\mathrm{IrO}_{2}$ surfaces were studied theoretically by means of $a b$ initio principles. All the calculations were performed using Density Functional Theory (DFT) and based on the Projector Augmented Wave ${ }^{31,32}$ (PAW) method as implemented in the Vienna Ab initio Simulation Package ${ }^{33-36}$ (VASP) - version 5.4.1. Generalized Gradient Approximation (GGA) was used for the exchange and correlation potential and all the calculations were carried out with the $\mathrm{PBEsol}^{37}$ functional. According to the PAW method, core electrons were kept frozen and replaced by pseudopotentials (Ir, O, C, H) and valence electrons (Ir: $6 s^{2} 5 d^{7} ;$ O: $2 s^{2} 2 p^{4} ; C: 2 s^{2} 2 p^{2} ; H: 1 s^{1}$ ) were expanded in a plane wave basis set with kinetic energy cutoff of $400 \mathrm{eV}$. With the PAW pseudopotentials used, scalar relativistic effects were taken into account the calculations. Spin orbit coupling effects were not included in our calculations because it has been shown that spin orbit did not affect significantly neither structural nor energetic properties of $\mathrm{IrO}_{2}{ }^{13,24}$. The Brillouin zone was sampled using Monkhorst-Pack ${ }^{38}$ scheme with a distance between k-points of $0.033 \AA^{-1}$ for structural optimizations and $0.020 \AA^{-1}$ for density of states (DOS) calculations. The choice of these parameters was justified by the high coherence between $\mathrm{IrO}_{2}$ bulk experimental data ${ }^{8,9,39,40}$ and computational one's. More details of the several tests performed are given in Supporting Information.

\section{B. Slab model}

In this study, (001), (100), (101) and (110) terminations of rutile $\mathrm{IrO}_{2}$ were investigated. These four stoichiometric surfaces were modeled as a two-dimensional slab in a threedimensional periodic cell. All our slabs were built with the MAPS suite ${ }^{41}$, with four $\mathrm{IrO}_{2}$ layers in thickness and a vacuum thickness of $20 \AA$ was introduced with the aim of avoid 
interactions between slabs. Energy convergence tests were performed on slab thickness, i.e. number of atomic layers, and on vacuum thickness in order to find the best compromise between accuracy and computational cost. The results of these tests, as well as the coordinates of the slabs for the four terminations, are given in Supporting Information.

First, the stoichiometric surfaces were optimized by relaxing positions of all the ions with the conjugate-gradient algorithm. Then, to compare the stability between the different terminations, surface energy was calculated following Eq. (1):

$$
\gamma_{h k l}=\frac{E_{\text {slabhkl}}-N E_{\text {bulk }}}{2 A_{h k l}}
$$

Where $E_{\text {slab hkl }}$ is the total energy of (hkl) slab, $E_{\text {bulk }}$ the total energy of bulk, $\mathrm{N}$ is the number of bulk unit in the slab, and $A_{h k l}$ is the (hkl) surface area. Finally, the DOS was calculated for all the terminations studied in the bare and adsorption systems.

\section{Adsorption}

The reactivity of the selected slabs was investigated by adsorption of the catechol molecule. Catechol has two anchoring points, it could bind with $\mathrm{IrO}_{2}$ surfaces according to three dissociative adsorption modes: bidentate (molecule bonded to two Ir sites via its two oxygen sites), chelated (molecule bonded to one Ir site via its two oxygen sites) and monodentate (molecule bonded to one Ir site via one oxygen site). Supercells were built from the fully relaxed slab model for each of the four surfaces in order to avoid interactions between catechol molecules and have approximately the same surface adsorption coverage for the

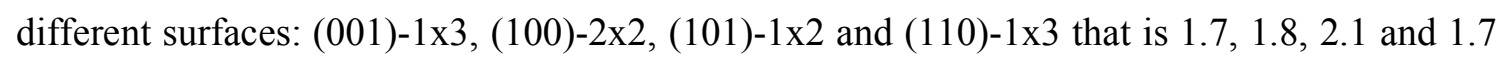
catechol $\cdot \mathrm{nm}^{-2}$, respectively. Otherwise, for this part of the study, the bottom-half of the slab was kept frozen during ionic relaxation to reduce computational cost. The top-half of the slab and the catechol molecule were optimized using the conjugate-gradient algorithm. The 
stability of the adsorption systems was determined by calculating adsorption energy as defined in Eq. (2).

$$
E_{\text {ads }}^{c a t}=E_{\text {slab,cat }}-\left(E_{\text {slab }}+E_{\text {cat }}\right)
$$

Where $E_{\text {slab,cat }}$ and $E_{\text {slab }}$ are the total energies of a slab with and without catechol molecule adsorbed, respectively, and $E_{c a t}$ is the total energy of catechol in gas phase (calculated in a box). Then the DOS of the most stable systems was calculated. Finally, charge transfers between surface and catechol molecule were investigated using Bader charge analysis ${ }^{42,43}$.

\section{Results \& Discussion}

\section{A. Slab: structural, energetic and DOS}

The (001), (100), (101) and (110) stoichiometric terminations are represented in Figure 1. From a structural point of view, terminations differ from: (i) the coordination number of surface atoms: O-2c, O-3c, Ir-4c, Ir-5c, and Ir-6c where $x c$ denotes the coordination of the atom to $x$ neighbors; (ii) the accessibility of atomic sites at the surface: (001) and (110) are "smooth" while (100) and (101) are uneven; and (iii) the nature of breaking bonds during bulk truncation: the bulk is formed of $\mathrm{IrO}_{6}$ octahedra with inequivalent $\mathrm{Ir}-\mathrm{O}$ axial and equatorial bonds. The slabs involving the least number of Ir-O bonds compared to the bulk are axial for (100) and (110), equatorial for (001) and (101). All these criteria can affect the properties and the reactivity of surfaces ${ }^{44}$, in particular in adsorption phenomena. For example, smooth surfaces have adsorption sites which are more accessible, and atoms with low coordination number are expected to be more reactive. 


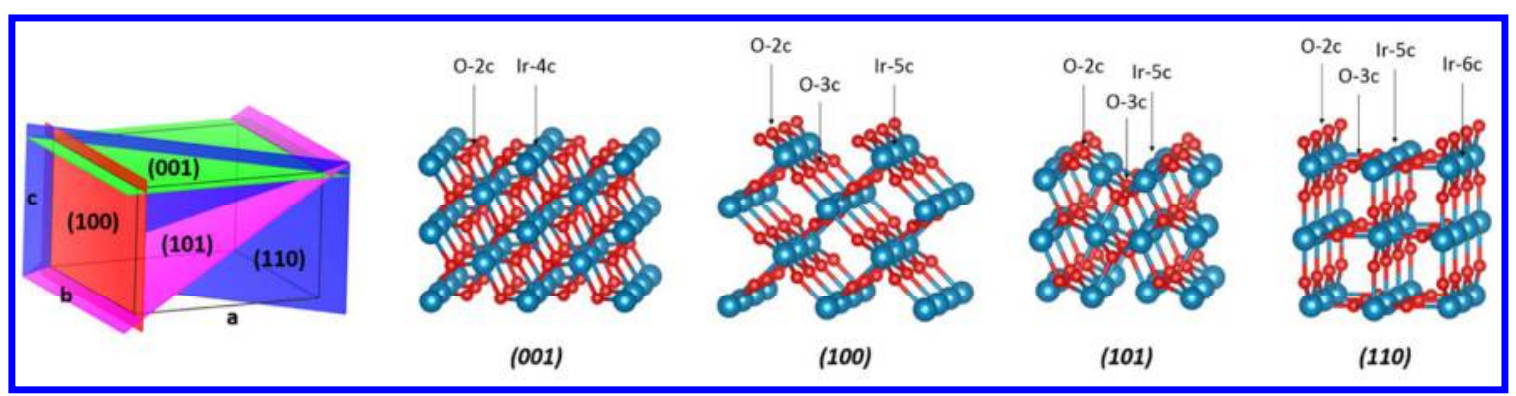

Figure 1. Representation in perspective of the (001), (100), (101) and (110) surfaces with coordination number of atoms at the surface where Ir-nc and $O-n c$ are iridium and oxygen of coordination number $n$. Iridium cations are represented in blue and oxygen anions in red. The bulk Ir-O bonds broken to create each termination are displayed in Figure S5.

(001) (100) (101) (110)

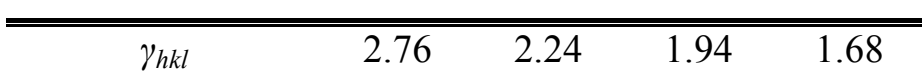

Ir-4c/Ir-5c/Ir-6c 5/-/- $\quad-/ 7 /-\quad-/ 8 /-\quad-/ 5 / 5$

O-2c/O-3c $\quad 10 /-\quad 7 / 7 \quad 8 / 8 \quad 5 / 10$

Table 1. Surface energy $\left(J \cdot \mathrm{m}^{-2}\right)$ and atom surface density (ions $\left.\cdot \mathrm{nm}^{-2}\right)$ in function of coordination number.

The surface energy was calculated for each slab as defined in Eq. 1 and is reported in Table 1 and Figure 2. Surface energy ranges between $1.7-2.8 \mathrm{~J} \cdot \mathrm{m}^{-2}$ and increases along the series: $(110)<(101)<(100)<(001)$. In this way, (110) corresponds to the most stable surface and (001) to the least one. It can be explained by the fact that the number of total bonds broken per surface unit is the lowest for (110) and the highest for (001) terminations: 10 and 20 broken bonds per squared nanometer, respectively. Due to the relaxation phenomena, the Ir$\mathrm{O}_{\text {surface }}$ bond distances are smaller compared to the bulk ones, and this for the four terminations studied. This phenomenon is very common and it is explained by the fact that the interactions between oxygen and metal are stronger compared to the bulk due to the low 
coordination number of atoms at the surface. However, depending on the termination, surface oxygens could be in axial or equatorial positions or both, and no relationship between the changes of bond distances after relaxation and the positions of the atoms (axial or equatorial) and the surface energy was observed. Indeed, surface relaxation increases along the series $(110)>(100)>(001)>(101)$, and so the relaxation trend did not follow the surface stability one. More details, including bond distance changes, are given in Supporting Information. Moreover, the equilibrium shape of $\mathrm{IrO}_{2}$ rutile crystal was estimated by means of the Wulff construction $^{45}$ and is depicted in Figure 2. Wulff construction allows depicting the equilibrium shape of a crystal from the surface energies of the more stable terminations. Indeed, a crystal reorganizes itself in such a way as to minimize its surface Gibbs free energy. According to the Wulff theorem, the distance from a surface to the center of mass is proportional to the surface energy and the envelope formed by these plans is the equilibrium shape of the crystal. Our Wulff structure is in perfect agreement with previous works ${ }^{22,24}$.

Figure 2 represents the values of surface energies calculated with different methods. It can be observed that the absolute values vary about $0.9 \mathrm{~J} \cdot \mathrm{nm}^{-2}$, the PBEsol values being the highest. This is explained by the fact that PBEsol overstabilizes the bulk compared to the surfaces rendering then a higher value for the surface energy. Nevertheless, the relative stability of the different terminations is the same whatever the functional used and the order of stability is unchanged. 


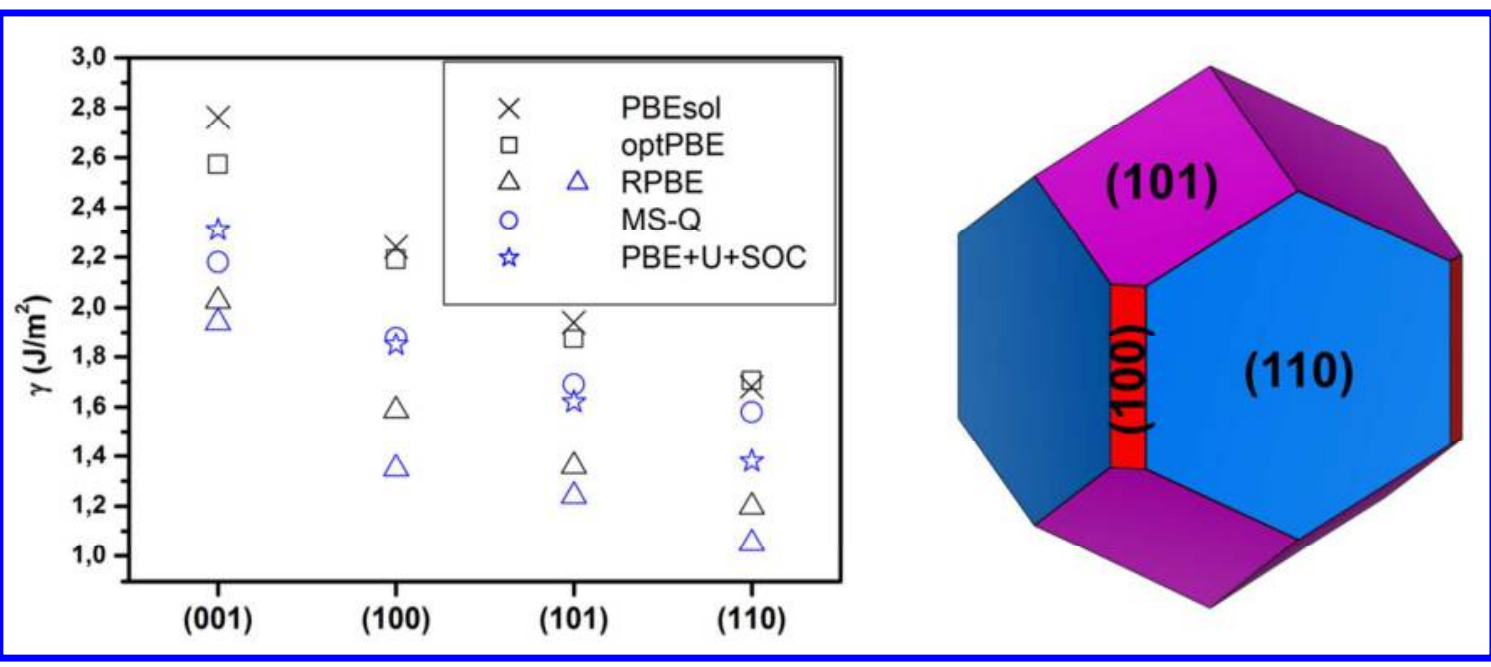

Figure 2. Left: surface energy $\left(J \cdot \mathrm{m}^{-2}\right)$ after relaxation. In black, the ones calculated in this study, and in blue Ref. ${ }^{22,24}$. Right: Wulff strucure for PBEsol functional.

The DOS is shown in Figure 3. Because of the absence of band gap near the Fermi level on all DOS, both bulk and surfaces exhibit metallic properties. It means that $\mathrm{IrO}_{2}$ surfaces keep the metallic properties of the bulk. DOS is consistent with most of ab initio works ${ }^{11,12,17,22}$ on the electronic properties of bulk $\mathrm{IrO}_{2}$ rutile. The bulk and surface DOS were very similar, with oxygen states (narrow band centered at $-20 \mathrm{eV}$, and a wider band centered at $-6 \mathrm{eV}$, corresponding with $\mathrm{O}-2 \mathrm{~s}$ and $\mathrm{O}-2 \mathrm{p}$ states, respectively; which are in good agreement with experimental results ${ }^{46-48}:-22$ and $-8 \mathrm{eV}$, respectively) and iridium states (wide band spread between $-2.5 \mathrm{eV}$ and $2 \mathrm{eV}$, thus containing the Fermi level, and a second band ranging from 2 to $5 \mathrm{eV}$ ). However, some differences between bulk and surface are observed: the states of surface sites are higher in energy compared to the bulk ones and lead to the appearance of peaks that were absent in the bulk DOS, like the peak at $-18 \mathrm{eV}$ (corresponding to surface oxygen $2 \mathrm{~s}$ states, detached from the bulk O-2s band centered at $-20 \mathrm{eV}$ ). Moreover, the local environment of the surface iridium states (see Figure S5) also has an impact in the DOS: the terminations where an axial Ir-O bond is missing, (100) and (110), show a sharp peak around $-3.5 \mathrm{eV}$ associated with the $\mathrm{O}-2 \mathrm{p}$ states and a small peak at $-8 \mathrm{eV}$ associated to iridium $\mathrm{d}$ 
states. The terminations where an equatorial Ir-O bond is missing, (101) and (001), show a more homogeneous DOS in the valence band region between -2.5 and $-7.5 \mathrm{eV}$.

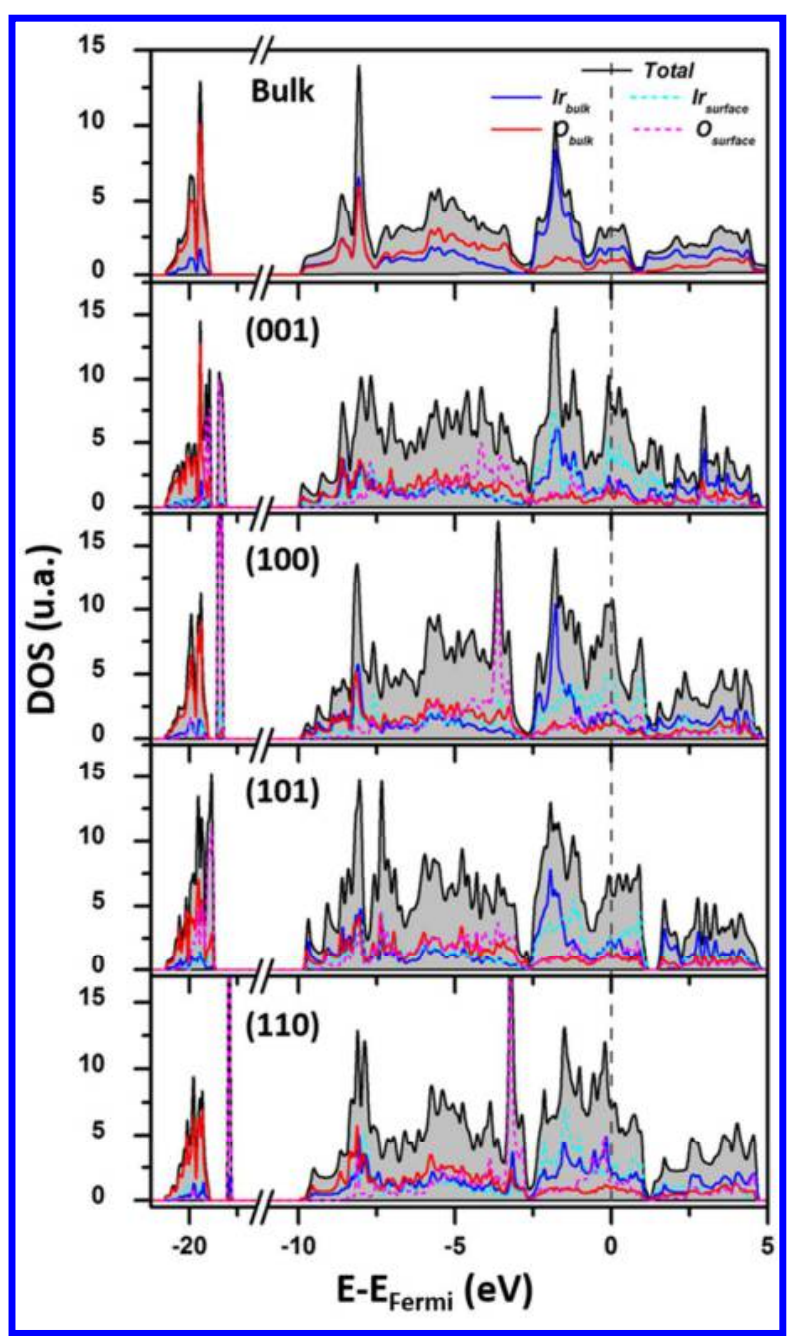

Figure 3. DOS and normalized Projected Density Of States (PDOS) for bulk and surfaces.

DOS are given in arbitrary unit and the Fermi level (dashed line) is set to $0 \mathrm{eV}$.

B. Catechol adsorption

Combined with a dye, $\mathrm{IrO}_{2}$ are widely used like photocatalysts ${ }^{30,49-52}$. Because of its chromophore properties and its small size, catechol is a molecule of choice to study interactions and bindings between dyes and $\mathrm{IrO}_{2}$ surfaces involved in photocatalytic process. Moreover, catechol has received a great attention with surfaces of $\mathrm{TiO}_{2}$ rutile and anatase ${ }^{53-58}$ due to its structural and electronic properties. 
Catechol has two hydroxyl groups (Figure 4), that could deprotonate giving rise to catecholate species with one or two protons. In the case of dissociative adsorption modes, catecholate oxygen(s) is bind to a low coordinated surface iridium site and the proton move to a low coordinated surface oxygen site. The deprotonation of catechol on $\mathrm{TiO}_{2}$ surfaces and nanoparticles has been reported in the literature from experimental and theoretical studies ${ }^{53,59-67}$ and we assume that the same behavior occur in $\mathrm{IrO}_{2}$. It can be explained by and acid-base adsorption mechanism ${ }^{59}$ where the protons of the molecule bind to the basic surface sites (oxygen) and the oxygens of the molecule bind to the surface acidic sites (iridium).

Catechol could bind to the surface according to three dissociative modes, displayed in Figure 4: monodentate (partial dissociation where catechol binds to one metallic site via its deprotonated oxygen), bidentate (full dissociation where molecule binds to two metallic sites with two deprotonated oxygens) and chelated (full dissociation where molecule is bind to one metallic site via its two deprotonated oxygens). The dissociative modes are accompanied of a deprotonation of the hydroxyl group, the proton is put on top of a low coordinated oxygen site in the slab model. But catechol can also adsorb according molecular mode, i.e. without deprotonation of hydroxyl group. Dissociative adsorption being significantly more stable than molecular adsorption, only monodentate, bidentate and chelate modes are presented in this study.

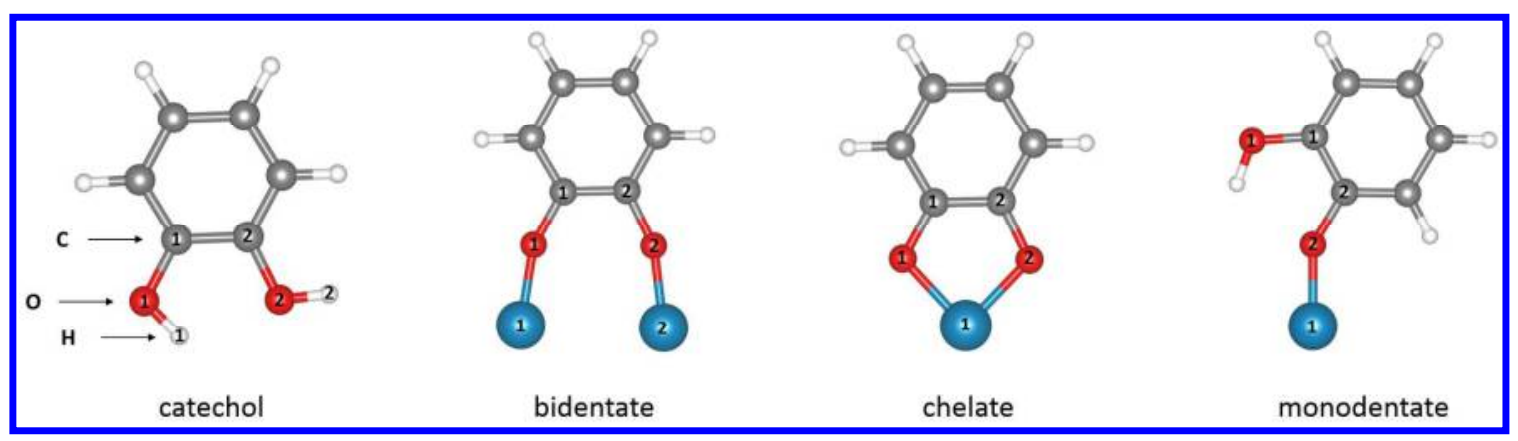

Figure 4. Representation of catechol molecule in gas phase (left) and the three dissociative adsorption modes. 
Table 2 summarizes the energetic and geometric results obtained in the present work. Catechol adsorption is exothermic for all the systems studied with adsorption energy ranged between -3.93 and $-1.51 \mathrm{eV} \cdot$ catechol $^{-1}$. Bidentate adsorption is systematically more stable than monodentate one for each termination. (001) surface with chelated mode and (110) surface with bidentate mode are the most reactive with adsorption energy of -3.93 and -3.83 $\mathrm{eV} \cdot$ catechol $^{-1}$, respectively. Due to their similar adsorption energies, the chelated adsorption on (001) is competing with bidentate adsorption on (110). The (101) surface is the least reactive with catechol with the highest adsorption energy for bidentate mode of $-2.23 \mathrm{eV}$. catechol $^{-1}$. Besides, only (001) surface allows chelate adsorption which can be explained by the fact that this is the only one to have iridium with coordination number of four at the surface. This result highlights the fact that the chelated mode can only be stabilized over (001) terminations, or alternatively surfaces containing undercoordinated $\mathrm{Ir}-4 \mathrm{c}$ sites, such as in nanoparticles or defective surfaces. Recently, some of us have shown that the adsorption mode of catechol in $\mathrm{TiO}_{2}$ clusters is intimately related to the optical properties: the chelated mode results in a significantly lower absorption threshold compared to the bidentate mode ${ }^{17}$, despite the fact that the bidentate mode is thermodynamically more stable. Our results indicate that the chelate mode could be selectively stabilized on (001) $\mathrm{IrO}_{2}$ terminations.

The bond lengths of $\mathrm{Ir}-\mathrm{O}_{\text {cat }}$ range between $2.046 \AA$ for (101) monodentate adsorption and $1.948 \AA$ for (100) bidentate adsorption. Although no correlation between bond lengths and adsorption energy are observed, the bonds are longer for monodentate than bidentate mode, except for the (001) surface where the opposite is observed. Moreover, (001) and (101) have longer $\mathrm{Ir}-\mathrm{O}_{\text {cat }}$ than (100) and (110) surfaces. It can be explained by the fact that $(001)$ and (101) have equatorial broken bonds at the surface unlike (100) and (110) exhibiting axial broken bonds. And it should be reminded that in the bulk, the distance $\mathrm{Ir}-\mathrm{O}_{\mathrm{eq}}$ is longer than Ir $-\mathrm{O}_{\mathrm{ax}}: 1.993$ and $1.958 \AA$, respectively. 
Furthermore, adsorption leads to structural modifications of catechol: on the one hand $\mathrm{C}-\mathrm{O}_{\text {cat }}$ shortening, on the other hand $\mathrm{C}_{1}-\mathrm{C}_{2}$ elongation, and this for all modes and surfaces. More precisely, bidentate mode is characterized by a significant elongation of $\mathrm{O}_{1 \text {,cat }}-\mathrm{O}_{2 \text {,cat }}$ : from $+0.142 \AA$ for $(001)$ to $+0.523 \AA$ for $(110)$. Indeed, this deformation of catechol can be understood by the fact that iridium sites at the surface try to find their octahedral geometry, and thus force catechol oxygens to occupy vacant sites. For the bidentate and chelate adsorptions, it is observed that the surface iridium atoms involved in the catechol adsorption restore their 6-fold coordination, this is accompanied by more exothermic adsorption energies. Indeed, in the case of (100) and (110) terminations where oxygens from catechol take an axial position, the $\mathrm{O}_{1, \text { cat }}-\mathrm{O}_{2 \text {,cat }}$ distance increases significantly in such way that the $\mathrm{Ir}$-Ir and the $\mathrm{O}_{1, \text { cat }}-\mathrm{O}_{2, \text { cat }}$ distances match very well: $d_{I r-I r}-d_{O_{1, \text { cat }}-O_{2, \text { cat }}}$ for (100) and (110) are 0.049 and $-0.053 \AA$, respectively. This means that the bulk-like configuration of the iridium sites involved is restored upon adsorption, and explain why the bidentate adsorption of catechol are very strong on these two surfaces. In the case of (001) and (101) surfaces, oxygens of catechol take the equatorial positions. For both of these surfaces, the comparison of the $\mathrm{O}_{1 \text {,cat }}-\mathrm{O}_{2 \text {,cat }}$ distance with the distance between the two respective surface oxygens at the same positions do not match: $d_{O_{1, e q}-O_{2, e q}}-d_{O_{1, c a t}-O_{2, c a t}}$ for $(001)$ and $(101)$ are 0.322 and $-0.270 \AA$, respectively. And so, the bulk-like configuration is not restored, explaining the fact that bidentate catechol adsorption on (001) and (101) surfaces is less stable than on (100) and (110). Figure 5 illustrates this point. 


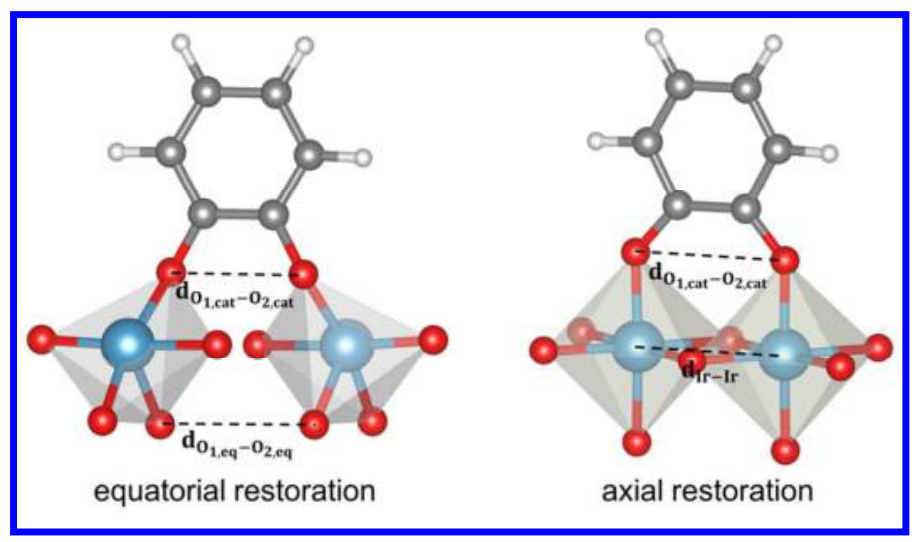

Figure 5. Schema illustrating the bulk-like configuration upon bidentate catechol adsorption.

Bader charge analysis was performed in order to study the charge transfer induced by catechol adsorption. For that purpose, Bader populations after adsorption of all catechol atoms were summed then subtracted to the total population of the molecule in gas phase. Bader charge analysis shows that catechol adsorption is systematically accompanied with a charge transfer from catechol to surface, and this for all the adsorption systems. This phenomenon was also observed in the case of adsorption on $\mathrm{TiO}_{2}{ }^{57}$. However, although charge transfers are more important for bidentate compared to monodentate mode, the quantity of transferred charge is not additive.

$(001)$

$(100)$

$(101)$

(110)

\begin{tabular}{|c|c|c|c|c|c|c|c|c|c|}
\hline & mono & bi & chel & mono & bi & mono & bi & mono & bi \\
\hline$E_{a d s}$ & -2.16 & -3.04 & -3.93 & -1.99 & -3.24 & -1.51 & -2.23 & -2.26 & -3.83 \\
\hline$q$ & +0.65 & +1.05 & +1.22 & +0.86 & +1.27 & +0.63 & +1.19 & +0.75 & +1.28 \\
\hline$d_{I r_{1} O_{1, c a t}}$ & I & 2.042 & 2.003 & I & 1.949 & I & 1.997 & I & 1.954 \\
\hline$d_{I r_{1} O_{2, c a t}}$ & 1.975 & / & 1.989 & 1.971 & / & 2.047 & / & 1.976 & / \\
\hline$d_{I r_{2} O_{2, c a t}}$ & I & 2.029 & I & I & 1.957 & I & 1.989 & / & 1.951 \\
\hline$\Delta d_{O_{1, c a t} O_{2, c a t}}$ & -0.041 & +0.141 & -0.057 & +0.021 & +0.464 & +0.036 & +0.381 & +0.093 & +0.523 \\
\hline
\end{tabular}


Table 2. Adsorption energy ( $E_{\text {ads }}$ in $\mathrm{eV} \cdot$ catechol $^{-1}$ ), Bader charge of catechol (q in $\left.|e|\right)$,

distance iridium-catechol oxygen ( $d$ in A) and distance difference between adsorbed (ads) and gas phase $(G P)$ catechol $\left(\Delta d=d_{a d s-c a t}-d_{G P-c a t}\right.$, in $\left.\AA\right)$.

Figure 6 shows the calculated DOS for catechol adsorption systems. Compared to clean surfaces, DOS after catechol adsorption are similar: peak positions and band widths are almost the same, meaning that catechol adsorption did not affect the electronic properties of the surface. However, strong hybridization between catechol and surface states is observed, corresponding to a large mixing of catechol and iridium states, especially in the upmost valence band $(-15$ to $+2 \mathrm{eV})$. This hybridization results mainly in the disappearance of welldefined pics for catechol (compared to the gas phase depicted in grey in Figure 6). Hybridization can explain the large adsorption energies observed (between -1.51 and $-3.93 \mathrm{eV}$ - catechol $^{-1}$ ), and more precisely, the larger the extent of hybridization, the larger the adsorption energy. 

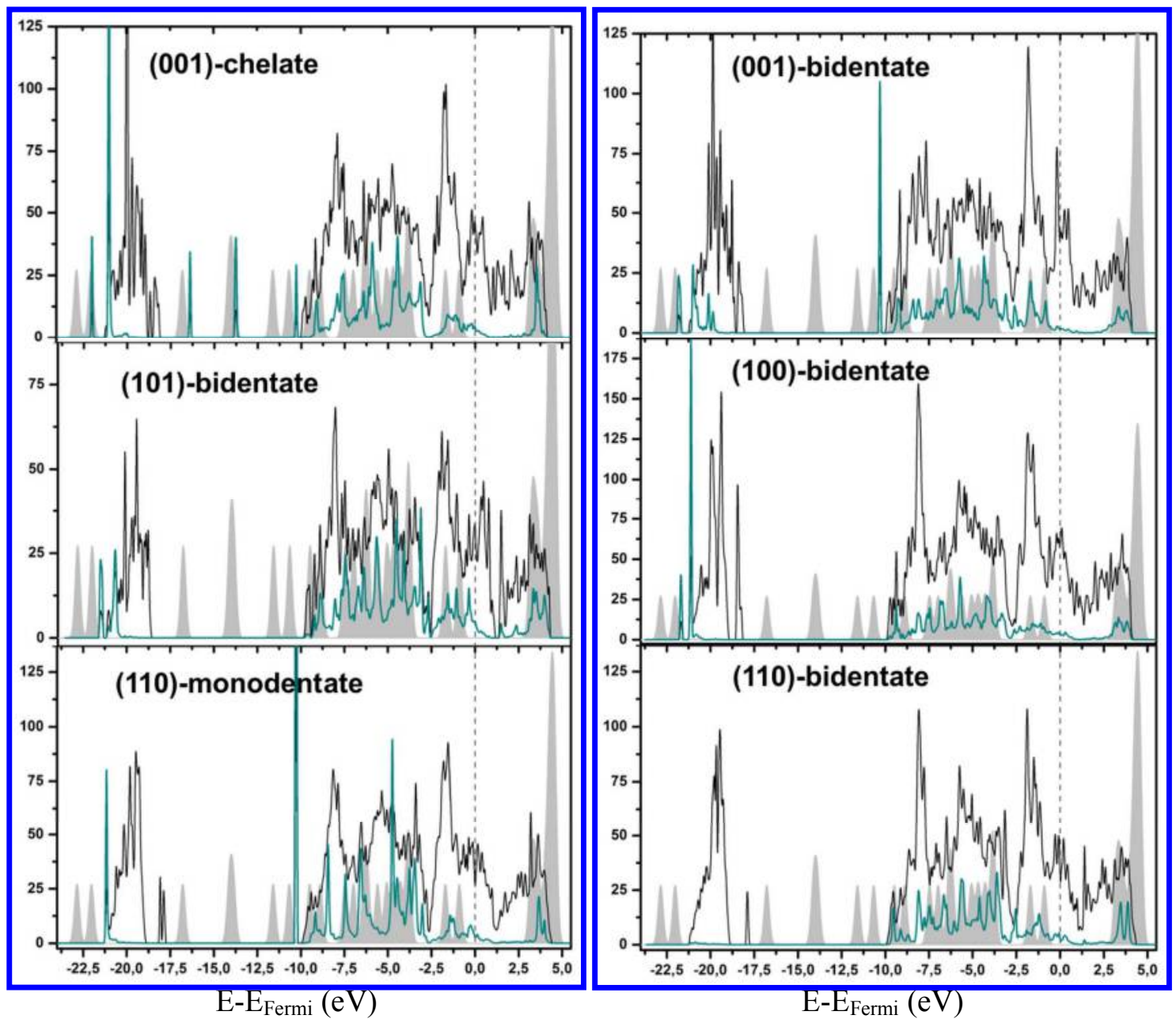

Figure 6. DOS total (black) and catechol PDOS x5 (green) for chelate, monodentate and bidentate adsorption modes. Fermi level is set to $0 \mathrm{eV}$ and DOS of catechol in gas phase is depicted in grey.

Compared to catechol in the gas phase, the adsorption systems do not exhibit peaks in the region between $-17.5 \mathrm{eV}$ and $-10 \mathrm{eV}$ (only one exception: monodentate on (101); see Supporting Information). The peaks corresponding to catechol in the valence band shift toward higher energy, for all the adsorption systems. It can be explained by charge transfer from molecule to the surface destabilizing the catechol molecules. Moreover, it was observed that peaks are better localized for monodentate than bidentate mode. It can be explained by two effects which contribute to create new states for catechol with bidentate adsorption: on 
the one hand a larger charge transfer and on the other hand a larger deformation of the molecule $\left(\Delta d_{O_{1, \text { cat }} O_{2, \text { cat }}}\right)$.

Catechol adsorption is accompanied by the molecular HOMO-LUMO gap decrease (Table 3), making in principle easier the electronic excitation. In order to evaluate how the adsorption of catechol changes its photoexcitation properties, the molecular HOMO-LUMO gap were calculated by making the difference between the energy of the lowest empty state and the highest occupied state of the molecule: $\Delta E_{\text {Номо-LUMO }}=E_{L U M O}-E_{\text {Номо }}$. A diminution of this molecular gap means that the catechol molecules will be more easily photoexcitable. Particularly in the case of bidentate adsorption on (101) where the HOMO-LUMO gap was reduced by half compared to gas phase: 1.86 and $4.21 \mathrm{eV}$, respectively. It was observed that gap diminution is larger for bidentate than monodentate mode, except for (001) surface where the HOMO-LUMO gap of bidentate mode is approximately equal to the one of gas phase molecule.

(001)

(100)

(101)

(110)

Gas phase

\begin{tabular}{lccccc}
\hline \hline monodentate & 3.81 & 3.74 & 2.69 & $3.91^{*}$ & \\
bidentate & 4.17 & $3.32^{*}$ & 1.86 & $3.46^{*}$ & 4.21 \\
chelated & 3.75 & & $/$ & &
\end{tabular}

Table 3. HOMO-LUMO gap of catechol: $\Delta E_{\text {cat }}^{\mathrm{HOMO}-\mathrm{LUMO}}(\mathrm{eV})$. * indicates hybridization between HOMO of catechol and Ir-5d states.

IV. Conclusion

The surface structure and reactivity of rutile $\mathrm{IrO}_{2}$ were studied by means of periodic density functional theory calculations. The stability of the terminations in vacuum was found to be $(110)>(101)>(100)>(001)$, and is related to the number of dangling bonds compared to the 
bulk. The electronic structure analyzed with the density of states indicates a metallic character for the bulk and all the surfaces studied, with iridium level not completely filled. The adsorption of catechol, used as a dye model, is found to be dissociative by full deprotonation, and energetically favorable. Interestingly, the most exothermic mode is chelated on the (001) termination, whereas the preferred mode for the other terminations is bidentate. The chelate (001) and the bidentate (110) are almost isoenergetic. This indicates a selective adsorption in a chelated mode over low-coordinated iridium sites such as those probably present in nanoparticles. The adsorption of catechol is accompanied by a charge transfer from the molecule to the surface, a hybridization of the surface-molecule bands and a decrease of the molecule HOMO-LUMO gap.

In the development of novel iridia-based PECs, the following points should be considered. First, the topology of the surface sites critically influences the adsorption mode of the linker: whereas 5-fold Ir leads to bidentate adsorption, the presence of 4-fold Ir leads to the stabilization of the chelated mode. Second, the catechol band gap decreases upon adsorption; this should have an impact in optical measurements. Third, catechol transfers electrons to the surface upon adsorption, with effect in both optical and catalytic activity. Our results may serve as a guide to design experiments aiming at establishing structure-properties relationships. In this sense, a controlled shape and size of iridia particles, or a specific surface termination, may ensure the presence of a given adsorption mode, allowing to perform a series of measurements on a well-defined system with only one adsorption mode. Thus, according to our results cubic particles exhibiting (001) facets, or a (001)-terminated single crystal, should adsorb selectively catechol in the chelated mode, while octahedral particles or other terminations lead to the stabilization of bidentate modes. The observations made on these systems (nuclear magnetic resonance, photoelectron spectroscopy, cyclic voltammetry, 
...) could thus be assigned to a certain species, enabling the possibility of discriminating the contribution of each species in a complex system.

Supporting Information

The results of the several tests on both bulk and slab, as well as the structure (POSCAR) of the four terminations studied are given in Supporting Information. Density of states for the monodentate adsorption systems is also provided in the Supporting Information file.

\section{Acknowledgment}

Authors acknowledge Scienomics for the MAPS program used in the construction of the slab models for a courtesy license. Dr. B. Diawara is acknowledged for the Modelview program. Dr. L. Gracia for valuable help regarding the Wulff construction. This work was performed using HPC resources from GENCI- CINES/IDRIS (Grants 2016- x2016082131, 2017- x2012082131), the CCRE-DSI of Université P. M. Curie for computational resources. This work has been carried out in the frame of the COST action CM1104 Reducible metal oxides.

\section{References}

(1) Fujishima, A.; Honda, K. Electrochemical Photolysis of Water at a Semiconductor Electrode. Nature 1972, 238, 37-38.

(2) Lewis, N. S.; Nocera, D. G. Powering the Planet: Chemical Challenges in Solar Energy Utilization. Proc. Natl. Acad. Sci. 2006, 103, 15729-15735.

(3) Young, K. J.; Martini, L. A.; Milot, R. L.; Snoeberger, R. C.; Batista, V. S.; Schmuttenmaer, C. A.; Crabtree, R. H.; Brudvig, G. W. Light-Driven Water Oxidation for Solar Fuels. Coord. Chem. Rev. 2012, 256, 2503-2520.

(4) Kamat, P. V.; Bisquert, J. Solar Fuels. Photocatalytic Hydrogen Generation. J. Phys. Chem. C 2013, 117, 14873-14875.

(5) Frame, F. A.; Townsend, T. K.; Chamousis, R. L.; Sabio, E. M.; Dittrich, T.; Browning, 
N. D.; Osterloh, F. E. Photocatalytic Water Oxidation with Nonsensitized $\mathrm{IrO}_{2}$ Nanocrystals under Visible and UV Light. J. Am. Chem. Soc. 2011, 13, 7264-7267.

(6) Kärkäs, M. D.; Verho, O.; Johnston, E. V.; Åkermark, B. Artificial Photosynthesis: Molecular Systems for Catalytic Water Oxidation. Chem. Rev. 2014, 114, 11863 12001.

(7) Pfeifer, V.; Jones, T. E.; Velasco Vélez, J. J.; Massué, C.; Greiner, M. T.; Arrigo, R.; Teschner, D.; Girgsdies, F.; Scherzer, M.; Allan, J.; et al. The Electronic Structure of Iridium Oxide Electrodes Active in Water Splitting. Phvs. Chem. Chem. Phvs. 2016, 18, 2292-2296.

(8) Bestaoui, N.; Prouzet, E.; Deniard, P.; Brec, R. Structural and Analytical Characterization of an Iridium Oxide Thin Layer. Thin Solid Films 1993, 235, 35-42.

(9) Bolzan, A. A.; Fong, C.; Kennedy, B. J.; Howard, C. J. Structural Studies of RutileType Metal Dioxides. Acta Crvstallogr. B 1997, 53, 373-380.

(10) Ono, S.; Brodholt, J. P.; Price, G. D. Structural Phase Transitions in $\mathrm{IrO}_{2}$ at High Pressures. J. Phvs. Condens. Matter 2008, 20, 045202.

(11) Hamad, B. A. First-Principle Calculations of Structural and Electronic Properties of Rutile-Phase Dioxides $\left(\mathrm{MO}_{2}\right), \mathrm{M}=\mathrm{Ti}, \mathrm{V}, \mathrm{Ru}, \mathrm{Ir}$ and Sn. Eur. Phvs. J. B 2009, 70, 163 169.

(12) Kahk, J. M.; Poll, C. G.; Oropeza, F. E.; Ablett, J. M.; Céolin, D.; Rueff, J.-P.; Agrestini, S.; Utsumi, Y.; Tsuei, K. D.; Liao, Y. F.; et al. Understanding the Electronic Structure of $\mathrm{IrO}_{2}$ Using Hard-X-Ray Photoelectron Spectroscopy and DensityFunctional Theory. Phvs. Rev. Lett. 2014, 112, 117601.

(13) Ping, Y.; Galli, G.; Goddard, W. A. Electronic Structure of $\mathrm{IrO}_{2}$ : The Role of the Metal d Orbitals. J.Phvs. Chem.C 2015, 119, 11570-11577.

(14) $\mathrm{Xu}, \mathrm{Z}$;; Kitchin, J. R. Tuning Oxide Activity through Modification of the Crystal and Electronic Structure: From Strain to Potential Polymorphs. Phvs. Chem. Chem. Phvs. 2015, 17, 28943-28949.

(15) Ryden, W. D.; Lawson, A. W.; Sartain, C. C. Electrical Transport Properties of $\mathrm{IrO}_{2}$ and $\mathrm{RuO}_{2}$. Phvs.Rev. B 1970, 1, 1494-1500.

(16) Liu, Y.; Masumoto, H.; Goto, T. Electrical and Optical Properties of $\mathrm{IrO}_{2}$ Thin Films Prepared by Laser-Ablation. Mater. Trans. 2004, 45, 3023-3027.

(17) de Almeida, J. S.; Ahuja, R. Electronic and Optical Properties of $\mathrm{RuO}_{2}$ and $\mathrm{IrO}_{2}$. Phys. Rev. B 2006, 73, 165102.

(18) Brewer, S. H.; Wicaksana, D.; Maria, J.-P.; Kingon, A. I.; Franzen, S. Investigation of the Electrical and Optical Properties of Iridium Oxide by Reflectance FTIR Spectroscopy and Density Functional Theory Calculations. Chem. Phvs. 2005, 313, 25 31.

(19) Zhao, Y.; Hernandez-Pagan, E. A.; Vargas-Barbosa, N. M.; Dysart, J. L.; Mallouk, T. E. A High Yield Synthesis of Ligand-Free Iridium Oxide Nanoparticles with High Electrocatalytic Activity. J. Phvs. Chem. Lett. 2011, 2, 402-406.

(20) He, Y. B.; Stierle, A.; Li, W. X.; Farkas, A.; Kasper, N.; Over, H. Oxidation of $\operatorname{Ir}(111)$ : From O-Ir-O Trilayer to Bulk Oxide Formation. J.Phvs. Chem. C 2008, 112, $11946-$ 11953.

(21) Pai, W. W.; Wu, T. Y.; Lin, C. H.; Wang, B. X.; Huang, Y. S.; Chou, H. L. A CrossSectional Scanning Tunneling Microscopy Study of $\mathrm{IrO}_{2}$ Rutile Single Crystals. Surf. Sci. 2007, 601, L69-L72.

(22) Novell-Leruth, G.; Carchini, G.; López, N. On the Properties of Binary Rutile $\mathrm{MO}_{2}$ Compounds, M = Ir, Ru, Sn, and Ti: A DFT Study. J. Chem. Phvs. 2013, 138, 194706.

(23) Rai, R.; Li, T.; Liang, Z.; Kim, M.; Asthagiri, A.; Weaver, J. F. Growth and Termination of a Rutile $\mathrm{IrO}_{2}(100)$ Layer on $\operatorname{Ir}(111)$. Surf. Sci. 2016, 652, $213-221$. 
(24) Sen, F. G.; Kinaci, A.; Narayanan, B.; Gray, S. K.; Davis, M. J.; Sankaranarayanan, S. K. R. S.; Chan, M. K. Y. Towards Accurate Prediction of Catalytic Activity in $\mathrm{IrO}_{2}$ Nanoclusters via First Principles-Based Variable Charge Force Field. J. Mater. Chem. A 2015, 3, 18970-18982.

(25) Pavlovic, Z.; Ranjan, C.; Gao, Q.; van Gastel, M.; Schlögl, R. Probing the Structure of a Water-Oxidizing Anodic Iridium Oxide Catalyst Using Raman Spectroscopy. ACS Catal. 2016, 6, 8098-8105.

(26) Wang, C.-C.; Siao, S. S.; Jiang, J.-C. Density Functional Theory Study of the Oxidation of Ammonia on the $\mathrm{IrO}_{2}$ (110) Surface. Langmuir 2011, 27, 14253-14259.

(27) Wang, C.-C.; Siao, S. S.; Jiang, J.-C. C-H Bond Activation of Methane via $\sigma-d$ Interaction on the $\mathrm{IrO}_{2}$ (110) Surface: Density Functional Theory Study. L. Phvs. Chem. C 2012, 116, 6367-6370.

(28) Valdés, Á.; Brillet, J.; Grätzel, M.; Gudmundsdóttir, H.; Hansen, H. A.; Jónsson, H.; Klüpfel, P.; Kroes, G.-J.; Le Formal, F.; Man, I. C.; et al. Solar Hydrogen Production with Semiconductor Metal Oxides: New Directions in Experiment and Theory. Phvs. Chem. Chem. Phvs. 2012, 14, 49-70.

(29) García-Melchor, M.; Vilella, L.; López, N.; Vojvodic, A. Computationally Probing the Performance of Hybrid, Heterogeneous, and Homogeneous Iridium-Based Catalysts for Water Oxidation. ChemCatChem 2016, 8, 1792-1798.

(30) Pastore, M.; De Angelis, F. First-Principles Modeling of a Dye-Sensitized $\mathrm{TiO}_{2} / \mathrm{IrO}_{2}$ Photoanode for Water Oxidation. J. Am. Chem. Soc. 2015, 137, 5798-5809.

(31) Blöchl, P. E. Projector Augmented-Wave Method. Phvs. Rev. B 1994, 50, 17953.

(32) Kresse, G.; Joubert, D. From Ultrasoft Pseudopotentials to the Projector AugmentedWave Method. Phys. Rev. B 1999, 59, 1758-1775.

(33) Kresse, G.; Hafner, J. Ab Initio Molecular Dynamics for Liquid Metals. Phys. Rev. B 1993, 47, 558-561.

(34) Kresse, G.; Hafner, J. Ab Initio Molecular-Dynamics Simulation of the Liquid-Metalamorphous-Semiconductor Transition in Germanium. Phvs. Rev. B 1994, 49, 1425114269.

(35) Kresse, G.; Furthmüller, J. Efficiency of Ab-Initio Total Energy Calculations for Metals and Semiconductors Using a Plane-Wave Basis Set. Comput._Mater. Sci. 1996, $6,15-50$.

(36) Kresse, G.; Furthmüller, J. Efficient Iterative Schemes for Ab Initio Total-Energy Calculations Using a Plane-Wave Basis Set. Phvs.Rev. B 1996, 54, 11169-11186.

(37) Perdew, J. P.; Ruzsinszky, A.; Csonka, G. I.; Vydrov, O. A.; Scuseria, G. E.; Constantin, L. A.; Zhou, X.; Burke, K. Restoring the Density-Gradient Expansion for Exchange in Solids and Surfaces. Phvs. Rev. Lett. 2008, 100, 136406.

(38) Monkhorst, H. J.; Pack, J. D. Special Points for Brillouin-Zone Integrations. Phys. Rev. $B$ 1976, 13, 5188-5192.

(39) CRC Handbook of Chemistry and Physics: A Ready-Reference Book of Chemical and Physical Data, 86. ed.; Chemical Rubber Company, Lide, D. R., Eds.; CRC Press: Boca Raton, 2005.

(40) Cordfunke, E. H. P. The Enthalpy of Formation of $\mathrm{IrO}_{2}$ and Thermodynamic Functions. Thermochim. Acta 1981, 50, 177-185.

(41) Scienomics - Explore anything in the world of materials. http://www.s16080558.onlinehome-server.info/ (accessed Jan 15, 2017).

(42) Tang, W.; Sanville, E.; Henkelman, G. A Grid-Based Bader Analysis Algorithm without Lattice Bias. J. Phvs. Condens. Matter 2009, 21, 84204.

(43) Yu, M.; Trinkle, D. R. Accurate and Efficient Algorithm for Bader Charge Integration. J. Chem. Phvs. 2011, 134, 64111. 
(44) Calle-Vallejo, F.; Loffreda, D.; Koper, M. T. M.; Sautet, P. Introducing Structural Sensitivity into Adsorption-energy Scaling Relations by Means of Coordination Numbers. Nat. Chem. 2015, 7, 403-410.

(45) Wulff, G. XXV. Zur Frage Der Geschwindigkeit Des Wachsthums Und Der Auflösung Der Krystallflächen. Z. Für Krist. - Cryst. Mater. 1901, 34.

(46) Riga, J.; Tenret-Noel, C.; Pireaux, J. J.; Caudano, R.; Verbist, J. J.; Gobillon, Y. Electronic Structure of Rutile Oxides $\mathrm{TiO}_{2}, \mathrm{RuO}_{2}$ and $\mathrm{IrO}_{2}$ Studied by X-Ray Photoelectron Spectroscopy. Phvs.Scr. 1977, 16, 351-354.

(47) Daniels, R. R.; Margaritondo, G.; Georg, C.-A.; Levy, F. Electronic States of Rutile Dioxides: $\mathrm{RuO}_{2}, \mathrm{IrO}_{2}$, and $\mathrm{Ru}_{\mathrm{x}} \mathrm{Ir}_{1-\mathrm{x}} \mathrm{O}_{2}$. Phys. Rev. B 1984, 29, 1813-1818.

(48) Kötz, R.; Stucki, S. Stabilization of $\mathrm{RuO}_{2}$ by $\mathrm{IrO}_{2}$ for Anodic Oxygen Evolution in Acid Media. Electrochim. Acta 1986, 31, 1311-1316.

(49) Yildiz, H. B.; Carbas, B. B.; Sonmezoglu, S.; Karaman, M.; Toppare, L. A Photoelectrochemical Device for Water Splitting Using Oligoaniline-Crosslinked $\left[\mathrm{Ru}(\text { bpy })_{2}\left(\text { bpyCONHArNH }{ }_{2}\right)\right]^{+2}$ Dye $/ \mathrm{IrO}_{2}$ Nanoparticle Array on $\mathrm{TiO}_{2}$ Photonic Crystal Modified Electrode. Int. J. Hvdrog. Energv 2016, 41, 14615-14629.

(50) Youngblood, W. J.; Lee, S.-H. A.; Kobayashi, Y.; Hernandez-Pagan, E. A.; Hoertz, P. G.; Moore, T. A.; Moore, A. L.; Gust, D.; Mallouk, T. E. Photoassisted Overall Water Splitting in a Visible Light-Absorbing Dye-Sensitized Photoelectrochemical Cell. $J$. Am. Chem. Soc. 2009, 131, 926-927.

(51) Osterloh, F. E. Inorganic Nanostructures for Photoelectrochemical and Photocatalytic Water Splitting. Chem. Soc. Rev. 2013, 42, 2294-2320.

(52) Zhao, Y.; Swierk, J. R.; Megiatto, J. D.; Sherman, B.; Youngblood, W. J.; Qin, D.; Lentz, D. M.; Moore, A. L.; Moore, T. A.; Gust, D.; et al. Improving the Efficiency of Water Splitting in Dye-Sensitized Solar Cells by Using a Biomimetic Electron Transfer Mediator. Proc. Natl. Acad.Sci. 2012, 109, 15612-15616.

(53) Duncan, W. R.; Prezhdo, O. V. Electronic Structure and Spectra of Catechol and Alizarin in the Gas Phase and Attached to Titanium. L. Phvs. Chem. B 2005, 109, 365373.

(54) Terranova, U.; Bowler, D. R. Adsorption of Catechol on $\mathrm{TiO}_{2}$ Rutile (100): A Density Functional Theory Investigation. J.Phvs. Chem.C 2010, 114, 6491-6495.

(55) Risplendi, F.; Cicero, G.; Mallia, G.; Harrison, N. M. A Quantum-Mechanical Study of the Adsorption of Prototype Dye Molecules on Rutile-TiO 2 (110): A Comparison between Catechol and Isonicotinic Acid. Phvs. Chem. Chem. Phvs. 2013, 15, 235-243.

(56) Mowbray, D. J.; Migani, A. Optical Absorption Spectra and Excitons of Dye-Substrate Interfaces: Catechol on $\mathrm{TiO}_{2}$ (110). J. Chem. Theory Comput. 2016, 12, 2843-2852.

(57) Luppi, E.; Urdaneta, I.; Calatayud, M. Photoactivity of Molecule-TiO ${ }_{2}$ Clusters with Time-Dependent Density-Functional Theory. J.Phvs. Chem. A 2016, 120, 5115-5124.

(58) Finkelstein-Shapiro, D.; Davidowski, S. K.; Lee, P. B.; Guo, C.; Holland, G. P.; Rajh, T.; Gray, K. A.; Yarger, J. L.; Calatayud, M. Direct Evidence of Chelated Geometry of Catechol on $\mathrm{TiO}_{2}$ by a Combined Solid-State NMR and DFT Study. L.Phvs. Chem.C 2016, 120, 23625-23630.

(59) Calatayud, M.; Markovits, A.; Menetrey, M.; Mguig, B.; Minot, C. Adsorption on Perfect and Reduced Surfaces of Metal Oxides. Catal. Todav 2003, 85, 125-143.

(60) Li, S.-C.; Wang, J.; Jacobson, P.; Gong, X.-Q.; Selloni, A.; Diebold, U. Correlation between Bonding Geometry and Band Gap States at Organic-Inorganic Interfaces: Catechol on Rutile $\mathrm{TiO}_{2}$ (110). J. Am. Chem. Soc. 2009, 131, 980-984.

(61) Liu, L.-M.; Li, S.-C.; Cheng, H.; Diebold, U.; Selloni, A. Growth and Organization of an Organic Molecular Monolayer on $\mathrm{TiO}_{2}$ : Catechol on Anatase (101). J. Am. Chem. Soc. 2011, 133, 7816-7823. 
(62) Rajh, T.; Tiede, D. M.; Thurnauer, M. C. Surface Modification of $\mathrm{TiO}_{2}$ Nanoparticles with Bidentate Ligands Studied by EPR Spectroscopy. L.Non-Crvst.Solids 1996, 205207, 815-820.

(63) Urdaneta, I.; Keller, A.; Atabek, O.; Palma, J. L.; Finkelstein-Shapiro, D.; Tarakeshwar, P.; Mujica, V.; Calatayud, M. Dopamine Adsorption on $\mathrm{TiO}_{2}$ Anatase Surfaces. J. Phvs. Chem. C 2014, 118, 20688-20693.

(64) Xu, Y.; Chen, W.-K.; Liu, S.-H.; Cao, M.-J.; Li, J.-Q. Interaction of Photoactive Catechol with $\mathrm{TiO}_{2}$ Anatase (101) Surface: A Periodic Density Functional Theory Study. Chem. Phvs. 2007, 331, 275-282.

(65) Sánchez-de-Armas, R.; San-Miguel, M. A.; Oviedo, J.; Márquez, A.; Sanz, J. F. Electronic Structure and Optical Spectra of Catechol on $\mathrm{TiO}_{2}$ Nanoparticles from Real Time TD-DFT Simulations. Phvs. Chem. Chem. Phvs. 2011, 13, 1506-1514.

(66) Sánchez-de-Armas, R.; San-Miguel, M. A.; Oviedo, J.; Sanz, J. F. Direct vs. Indirect Mechanisms for Electron Injection in DSSC: Catechol and Alizarin. Comput. Theor. Chem. 2011, 975, 99-105.

(67) Redfern, P. C.; Zapol, P.; Curtiss, L. A.; Rajh, T.; Thurnauer, M. C. Computational Studies of Catechol and Water Interactions with Titanium Oxide Nanoparticles. $J$. Phvs. Chem. B 2003, 107, 11419-11427.

TOC Graphic

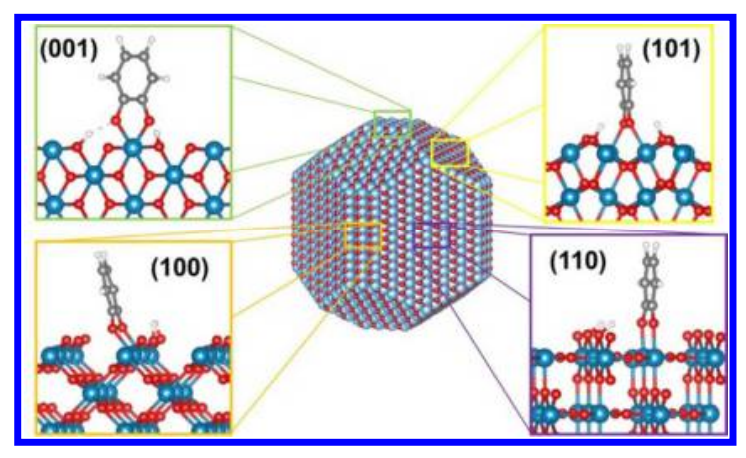

